\title{
Highly branched triple-chain surfactant-mediated electrochemical exfoliation of graphite to obtain graphene oxide: colloidal behaviour and application in water treatment
}

\author{
Nur Amirah Jamaluddin, Azmi Mohamed, \\ Suriani Abu Bakar, Tretya Ardyani, Masanobu Sagisaka, \\ Shota Suhara, Mohamad Hafiz Mamat, Mohd Khairul \\ Ahmad, Stephen M. King, Sarah E. Rogers and Julian Eastoe
}

\section{Published version information}

Citation: NA Jamaluddin et al. "Highly branched triple-chain surfactant-mediated electrochemical exfoliation of graphite to obtain graphene oxide: colloidal behaviour and application in water treatment." Physical Chemistry Chemical Physics, vol. 22, no. 22 (2020): 12732-12744.

DOI: $\underline{10.1039 / d 0 c p 01243 b}$

This version is made available in accordance with publisher policies. Please cite only the published version using the reference above. This is the citation assigned by the publisher at the time of issuing the AAM. Please check the publisher's website for any updates. 

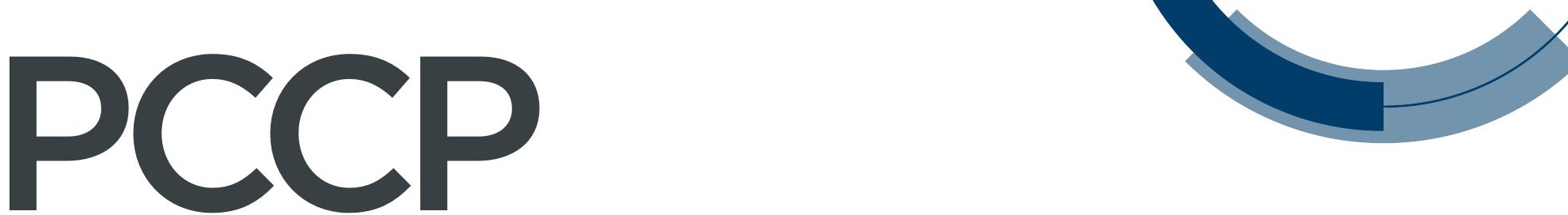

Physical Chemistry Chemical Physics

\section{Accepted Manuscript}

This article can be cited before page numbers have been issued, to do this please use: N. A. Jamaluddin, A. Mohamed, S. Abu Bakar, T. Ardyani, M. Sagisaka, S. Suhara, M. Hafiz Mamat, M. K. Ahmad, S. M. King, S.

E. Rogers and J. Eastoe, Phys. Chem. Chem. Phys., 2020, DOI: 10.1039/D0CP01243B.
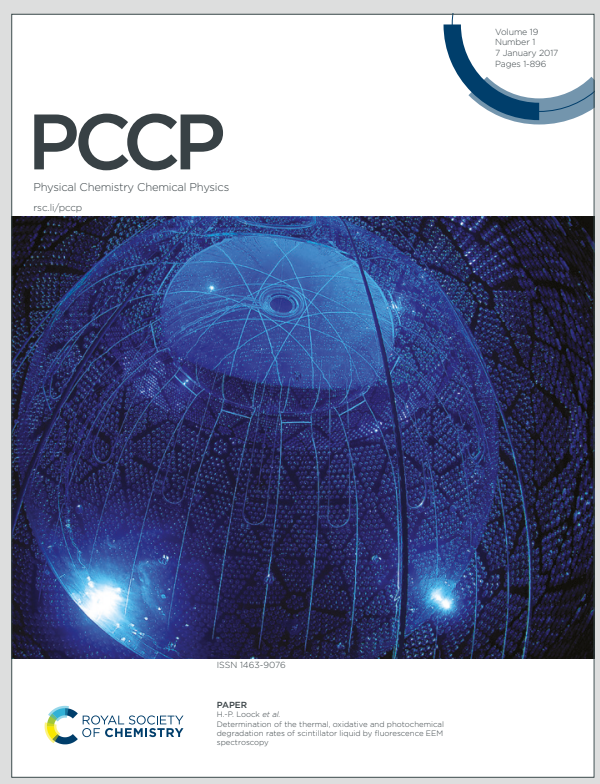

This is an Accepted Manuscript, which has been through the Royal Society of Chemistry peer review process and has been accepted for publication.

Accepted Manuscripts are published online shortly after acceptance, before technical editing, formatting and proof reading. Using this free service, authors can make their results available to the community, in citable form, before we publish the edited article. We will replace this Accepted Manuscript with the edited and formatted Advance Article as soon as it is available.

You can find more information about Accepted Manuscripts in the Information for Authors.

Please note that technical editing may introduce minor changes to the text and/or graphics, which may alter content. The journal's standard Terms \& Conditions and the Ethical guidelines still apply. In no event shall the Royal Society of Chemistry be held responsible for any errors or omissions in this Accepted Manuscript or any consequences arising from the use of any information it contains. 


\title{
ARTICLE
}

\section{Highly Branched Triple-chain Surfactant-mediated Electrochemical Exfoliation of Graphite to Obtain Graphene Oxide: Colloidal Behaviour and Application in Water Treatment}

Received 00th January 20xx, Accepted 00th January 20xx DOI: $10.1039 / \times 0 \times x 00000 x$

Nur Amirah Jamaluddin, a Azmi Mohamed, ${ }^{* a, b}$ Suriani Abu Bakar, b Tretya Ardyani, a Masanobu Sagisaka, ${ }^{c}$ Shota Suhara, ${ }^{c}$ Mohamad Hafiz Mamat, ${ }^{d}$ Mohd Khairul Ahmad, e Stephen M. King, ${ }^{f}$ Sarah E. Rogers, ${ }^{f}$ and Julian Eastoe $\mathrm{g}$

\begin{abstract}
The generation of surfactant-assisted exfoliated graphene oxide (sEGO) by electrochemical exfoliation is influenced by the presence of surfactants, and in particular the hydrophobic tail molecular-architecture. Increasing surfactant chain branching may improve the affinity for the graphite surfaces to provide enhanced intersheet separation and stabilisation of exfoliated sheets. The resulting SEGO composites can be readily used to remove of a model pollutant, the dye, methylene blue (MB), from aqueous solutions by providing abundant sites for dye adsorption. This article explores relationships between surfactant structure and the performance of $\mathrm{SEGO}$ for MB adsorption. Double-branched and highly branched triple-chain graphene-compatible surfactants were successfully synthesised and characterised by ${ }^{1} \mathrm{H}$ NMR spectroscopy. These surfactants were used to produce $\mathrm{SEGO}$ via electrochemical exfoliation of graphite, and the sEGOs generated were further utilised in batch adsorption studies of $M B$ from aqueous solutions. The properties of these synthesised surfactants were compared with those of a common single-chain standard surfactant, sodium dodecyl-sulfate (SDS). The structural morphology of sEGO was assessed using Raman spectroscopy and field emission scanning electron microscopy (FESEM). To reveal the links between the hydrophobic chain structure and the sEGO adsorption capacity, UVvisible spectroscopy, zeta potential, and air-water $(\mathrm{a} / \mathrm{w})$ surface tension measurements were conducted. The aggregation behaviour of the surfactants was studied using small-angle neutron scattering (SANS). The highly branched triple-chain surfactant sodium 1,4-bis(neopentyloxy)-3-(neopentylcarbonyl)-1,4-dioxobutane-2-sulfonate (TC14) displayed enhanced exfoliating efficiency compared to those of the single-and double-chain surfactants, leading to $~ 83 \% \mathrm{MB}$ removal. The findings suggest that highly branched triple-chain surfactants are able to offer more adsorption sites, by expanding the sEGO interlayer gap for MB adsorption, compared to standard single-chain surfactants.
\end{abstract}

\section{Introduction}

Water contamination has been a major environmental issue for many years. Various contaminants, such as organic dyes, ${ }^{1}$ heavy metals (e.g., copper and lead), ${ }^{2-4}$ and unwanted materials (e.g.,

a. Department of Chemistry, Faculty of Science and Mathematics, Universiti Pendidikan Sultan Idris, 35900 Tanjong Malim, Perak, Malaysia.

b. Nanotechnology Research Centre, Faculty of Science and Mathematics, Universiti Pendidikan Sultan Idris, 35900 Tanjong Malim, Perak, Malaysia.

Department of Frontier Materials Chemistry, Graduate School of Science and Technology, Hirosaki University, Bunkyo-cho 3, Hirosaki, Aomori 036-8561, Japan.

d. NANO-ElecTronic Centre (NET), Faculty of Electrical Engineering, Universiti

Teknologi MARA (UiTM), 40450 Shah Alam, Selangor, Malaysia.

e. Microelectronic and Nanotechnology - Shamsuddin Research Centre (MiNT-SRC),

Faculty of Electrical and Electronic Engineering, Universiti Tun Hussein Onn Malaysia, 86400 Parit Raja, Batu Pahat, Johor, Malaysia.

f. ISIS Pulsed Neutron \& Muon Source, STFC Rutherford Appleton Laboratory,

Harwell Campus, Didcot, Oxfordshire, OX11 OQT, United Kingdom.

g. School of Chemistry, University of Bristol, Cantock's Close, Bristol, BS8 1TS, United Kingdom. Email: azmi.mohamed@fsmt.upsi.edu.my

Electronic Supplementary Information (ESI) available: [details of any supplementary information available should be included here]. See DOI: $10.1039 / x 0 x x 00000 x$ selenium), ${ }^{5}$ many of which are toxic, are discharged into receiving waters, imparting undesirable colour (in the case of dyes) and health effects. Methylene blue (MB) is among the most frequent anthropogenic water contaminants, being an aromatic cationic dye that is widely used in the textile, ${ }^{6}$ paper and agrochemical industries $^{7}$. Hence, there is a pressing need to eliminate this pollutant from wastewater and find effective and economical adsorbents for water treatment.

In general, adsorption is the most favoured method for eliminating dye from aquatic environments because it is simple and economical, offers high removal efficiency at low operational cost, generates minimal secondary by-products (e.g., sludge formation), and is able to separate a wide range of pollutants. There are various mechanisms for adsorption, such as bulk diffusion, external mass transfer, chemisorption or intraparticle diffusion. ${ }^{8}$ The adsorption process itself can be physical (dominated by van der Waals interactions) or chemical (ionic or covalent bonding between the adsorbate and adsorbent). ${ }^{9}$

Traditional carbon-based adsorbents for MB effluents, such as activated carbon $(A C)$, have been successfully deployed for many 
years because they are reasonably effective and inexpensive. More recently, however, interest has been directed towards emerging advanced carbon nanomaterials, such as carbon nanotubes (CNTs), and how these materials might be used in wastewater treatment. Nevertheless, AC is not always effective at removing all contaminants as it is susceptible to clogging and fouling ${ }^{7}$ and whilst CNTs can outperform AC, they are not yet cost-effective. ${ }^{9,10}$ Hence, there is a potential interest in alternative carbon-based adsorbents.

Ever since the discovery of graphene by Geim and Novoselov in $2004,{ }^{11}$ graphene-based materials have attracted substantial interest and have been evaluated for various applications. ${ }^{2-4}$ Recently, for wastewater treatment there has been increased focus on graphene oxide (GO). ${ }^{15}$ Since $\mathrm{GO}$ possesses a high surface area to mass ratio $\left(736.6 \mathrm{~m}^{2} \mathrm{~g}^{-1}\right)^{16}$ and includes polar oxygen functional groups, GO is strongly hydrophilic and demonstrates good dispersibility in aqueous systems. ${ }^{17}$ Being negatively charged, GO is suitable for treating wastewater containing positively charged pollutants by promoting hydrogen bonding or electrostatic interactions. ${ }^{8}$ The production of GO is also rather straightforward and can be performed at reasonable cost from cheap natural graphite deposits. ${ }^{18}$

As pointed out by Heard, ${ }^{19}$ the method of GO production can be tailored based on the target application. There are several methods to generate GO, including the modified Hummers method, ${ }^{21,22}$ chemical vapour deposition (CVD), ${ }^{23,24}$ epitaxial growth, ${ }^{24}$ and liquid-phase exfoliation (LPE) or electrochemical exfoliation of graphite. ${ }^{26-28}$ Among these methods, electrochemical exfoliation facilitated by surfactants, is simple and also less hazardous than the Hummers' method. The surfactants used in this process promote intercalation and exfoliation of graphite and formation of oxidized GO. ${ }^{28}$ As such, surfactant-facilitated exfoliation of graphite can be considered an appealing method for graphene production. ${ }^{29-32}$ Electrochemical exfoliation has been explored with approaches involving sulfuric $\operatorname{acid}^{33,34}$ and sodium sulfate solution ${ }^{35}$ as electrolytes.

The ability of surfactants to adsorb at interfaces and selfassemble as micelles is beneficial for intercalation within graphene layers ${ }^{30,31}$ and promotes additional GO surface area to further enhance adsorption. Although several studies have been performed, ${ }^{42,53,77}$ understanding about the role of adsorbed surfactant in GO production, and for the dye removal process is still quite sparse. Moreover, recent literature has mainly focused on the effectiveness and optimization of exfoliation, where the surfactant only acts as a stabilizing agent, ${ }^{15}$ rather than addressing the fundamentals of the contaminant and dye removal process. Ideally, the goal is to develop surfactants that will simultaneously promote both efficient exfoliation and dye removal.

A previous study using ionic surfactants revealed that varying the number of surfactant chains (one, two or three surfactant tails) enhances the compatibility between graphene surfaces and surfactant molecules, facilitating improved exfoliation. ${ }^{38}$ Along similar lines, in this work, the surfactants are also designed with different numbers of chains to improve their graphene compatibility. Here, the production of a few layers of graphene oxide via electrochemical exfoliation is investigated with added

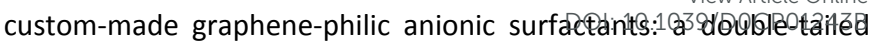
surfactant, AOT-14 (sodium bis(3,3,3-trimethyl-1-propyl) sulfosuccinate), and a triple-tailed surfactant, TC14 (sodium 1,4bis(neopentyloxy)-3-(neopentylcarbonyl)-1,4-dioxobutane-2sulfonate) (see Table 1). The term surfactant/graphene composite (sEGO) will be used throughout this article to refer to the graphene oxide materials generated in this way. To investigate the effect of surfactant chemical structure the performance of these customsynthesised surfactants was compared with the common single-tail anionic surfactant SDS (sodium dodecylsulfate, Table 1). It was found that a enhanced methylated and branched chain structures bestow enhanced adsorption capacity on these $\mathrm{SEGO}$, with up to 82.7\% MB removal from aqueous solutions. The results presented here indicate new possibilities for direct (in situ) applications of surfactant-exfoliated graphene oxides as adsorbent materials and provide a platform for the generation of future surfactants for carbon nanomaterial-based water treatments.

\section{Materials and Methods}

\section{Materials}

TC14 and AOT14 were synthesised as previously. ${ }^{40,41}$ 2,2-Dimethyl propanol (Acros, 99\%) SDS (Systerm, 99\%), and deuterium oxide (Apollo Scientific Limited, 99\%) were used as received. For the adsorption study, a general purpose grade of MB was purchased from Fisher Chemical and used without further purification. Detailed information regarding the surfactant characterization is given in the Supplementary Material.

\section{Preparation of surfactant-assisted electrochemically exfoliated graphene oxide (sEGO)}

sEGO was obtained through electrochemical exfoliation of graphite in surfactant solutions. ${ }^{41}$ Three different anionic surfactants, namely, SDS, AOT14 and TC14, were used as the electrolytes with a concentration of $0.05 \mathrm{M}$ following the previous approach of Suriani et al. ${ }^{41} \mathrm{High}$-purity graphite rods (diameter $10 \mathrm{~mm}$ and length 15 $\mathrm{cm}$, Model MV10) were used as carbon electrodes, and exfoliation was carried out for $24 \mathrm{~h}$ by applying a potential of $7 \mathrm{~V}$ to the graphite electrodes using a GW INSTEK GPS 3030DD power supply. A schematic illustration of the SEGO preparation process is presented in Fig. S3. 
Table 1 Surfactants used in this study

Surfactant Name Surfactant Structure and Name

SDS

AOT14

TC14

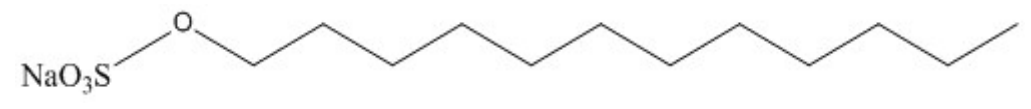

sodium dodecylsulfate<smiles>CC(C)(C)COC(=O)CC(C(=O)OCC(C)(C)C)[S+]([O])([O-])[O-]</smiles>

sodium 1,2-bis-(2,2-dimethyl-propoxycarbonyl)-ethanesulfonate<smiles>CC(C)(C)COC(=O)CC(C(=O)OCC(C)(C)C)C(C(=O)OCC(C)(C)C)[S+](C)(=O)=O</smiles>

sodium 1,4-bis(neopentyloxy)-3-(neopentyloxycarbonyl)-1,4-dioxobutane-2-sulfonate

To complete exfoliation the sEGO obtained was then sonicated (Model 5510, Branson) for $1 \mathrm{hr}$. to generate dispersions. To determine the mass of SEGO in suspension, the graphite rods were weighed before and after exfoliation (refer to Table S3 for further details). It is important to note that added surfactants are crucial components for the electrolyte, as exfoliation does not occur without surfactant.

\section{Preparation of sEGO adsorbents and dye solutions}

A known amount of sEGO suspension was adjusted to neutral $\mathrm{pH}$ with $0.1 \mathrm{M} \mathrm{NaOH}$ and $0.1 \mathrm{M} \mathrm{HCl}$ using a Thermo Orion 2 Star $\mathrm{pH}$ Benchtop Meter. Dye solutions were prepared by dissolving appropriate amounts of MB in deionized water. The stock solutions were diluted to the required concentrations and adjusted to neutral $\mathrm{pH}$ as well (see Fig. S5).

\section{Adsorption of methylene blue (MB) on sEGO}

Batch adsorption experiments were conducted by adding a prerequisite amount of neutral-pH MB (see Table S3) to sEGO suspensions prepared in $250 \mathrm{~mL}$ Erlenmeyer flasks. The flasks containing sEGO and dye solution were sealed and shaken at a constant speed of $110 \mathrm{rpm}$ using an orbital shaker (Protech Model 720). The effect of initial MB concentration in the range of $5-15$ $\mathrm{mg} / \mathrm{L}$ was studied and contact time was varied from $15-1440$ mins. At the end of the equilibration period, $1 \mathrm{~mL}$ of sample was taken from the $S E G O / M B$ dispersion and then subjected to centrifugation at $6000 \mathrm{rpm}$ for $5 \mathrm{~min}$. The concentration of MB in the supernatant was measured using a UV-Vis spectrophotometer (Shimadzu 1800) at $\lambda_{\max } 664 \mathrm{~nm}$ (optimum wavelength) with a $1 \mathrm{~cm}$ cuvette.

The percentage of $\mathrm{MB}$ removal (R\%) from the aqueous solution was calculated using eqn (1). Eqn (2) was used to calculate the adsorbed amount of MB.

$$
\begin{aligned}
& \mathrm{R} \%=\left(\frac{\mathrm{C}_{0}-\mathrm{Ce}_{\mathrm{e}}}{\mathrm{C}_{0}}\right) \times 100 \\
& \mathrm{qe}=\frac{\left(\mathrm{C}_{0}-\mathrm{Ce}_{\mathrm{e}}\right) \mathrm{V}}{\mathrm{W}}
\end{aligned}
$$

where $\mathrm{q}_{\mathrm{e}}$ is the amount of $\mathrm{MB}$ adsorbed per gram adsorbent $(\mathrm{mg} / \mathrm{g}), C_{0}$ is the initial $\mathrm{MB}$ concentration $(\mathrm{mg} / \mathrm{L}), C_{e}$ is the equilibrium $\mathrm{MB}$ concentration ( $\mathrm{mg} / \mathrm{L}$ ), $\mathrm{V}$ is the volume of solution ( $\mathrm{L}$ ) and $W$ is the mass of adsorbent $(\mathrm{g})$. The adsorption experiments were performed in triplicate. To investigate whether the presence of surfactants in SEGO may alter the adsorption process, it is instructive to measure the system with surfactant solely as an 
adsorbent. To provide a comparison, data were collected at similar initial concentrations to those in systems containing SEGO. An attempt to use the surfactants for MB adsorption without SEGO resulted in a negligible removal of less than $1 \%$ for all surfactants used in this study.

\section{sEGO morphology characterization}

The morphology and structure of SEGO was investigated using field emission scanning electron microscopy (FESEM, Hitachi SU8020). Raman spectra of sEGO were collected using a Renishaw InVia micro Raman spectrophotometer with a wavelength of $514 \mathrm{~nm}$.

\section{Zeta potential measurement of $\mathrm{SEGO}$ suspension}

The colloidal stability of SEGO was assessed by determining the surface charge properties as characterized using an ELSZ-1000 zeta potential and particle size analyser (Photal OTSUKA ELECTRONICS) with the Smoluchowski equation as the zeta potential conversion equation and single-peak Lorentz fitting. Measurements were carried out in a flow cell with sampling time $400 \mu \mathrm{s}$, accumulation number 7 , measuring angle $15^{\circ}$, temperature $25^{\circ} \mathrm{C}$, pin hole size 50 $\mu \mathrm{m}$, and cell constant $70.000 \mathrm{~cm}^{-1}$. The properties of water (refractive index 1.3328, viscosity $0.8878 \mathrm{cP}$, and permittivity 78.3 $\mathrm{Fm}^{-1}$ ) were used for the calculation of the zeta potential. Zeta potential values were finally obtained as average values of 10 runs for each sample.

\section{Small-angle neutron scattering measurements}

The small-angle neutron scattering (SANS) experiments were performed using the time-of-flight diffractometer LOQ instrument at the ISIS Pulsed Neutron \& Muon Source, UK. The accessible Q range was $0.007-0.23 \AA^{-1}$, arising from incident neutron wavelengths of $\lambda=2.2-10 \AA$ at $25 \mathrm{~Hz}$. The samples for SANS were prepared in deuterium oxide $\left(D_{2} \mathrm{O}\right)$ to enhance the neutron contrast and improve signal-to-noise, contained in $2 \mathrm{~mm}$ path-length quartz cells and held in a thermostatted computer-controlled sample changer at $25^{\circ} \mathrm{C}$. Absolute scattering intensities $I(Q)\left(\mathrm{cm}^{-1}\right)$ were determined to be within $5 \%$ by measuring the scattering from a partially deuterated polymer standard of known molecular weight and hence known $I(Q=0)$. The instrument-independent reduced SANS data generated using the Mantid framework (www.mantidproject.org), were then model-fit using the SasView program (www.sasview.org) by constraining scattering length densities and other known parameters to a priori values. Unknown structural parameters were allowed to be refined during the fitting process to obtain an optimized fit as required by the different scattering model functions. The SANS data are presented as a function of the (magnitude of the) scattering vector, $Q=(4 \pi / \lambda)$ $\operatorname{Sin}(\theta)$, where $\theta$ is half of the scattering angle. The approximate size of a feature is thus $2 \pi / Q$.

\section{Surface tension measurements}

Air-water $(\mathrm{a} / \mathrm{w})$ surface tension values for the surfactants and sEGO were determined using a Willhelmy tensiometer (CBVP-A3, Kyowa Interface Science) equipped with a platinum plate. All measurements were taken at $25^{\circ} \mathrm{C}$ once the surface tension of the

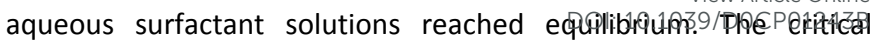
micelle concentrations $(\mathrm{cmc})$ of each surfactant were determined from the intersection of the surface tension $(\gamma)$ versus In(concentration) plots.

\section{Results and Discussion}

\section{Adsorption studies: Effect of operating parameters}

The adsorption activity (percentage dye removal and adsorption capacity) of an adsorbent is affected by various parameters, such as the initial dye concentration, contact time, solution $\mathrm{pH}$, mass of adsorbent and temperature. ${ }^{7,43,44}$ In this work the effect of initial dye concentration and contact time were considered for the batch adsorption analyses. Related parameters, i.e., pH and mass of adsorbent, were fixed throughout. According to Haubner et al. ${ }^{44}$ a higher $\mathrm{pH}$ leads to weaker electrostatic interactions, which will affect dye removal; hence, a neutral pH was used. It is also known that the amount of adsorbent will significantly affect the adsorption capacity, and the optimum mass was determined to be $5 \mathrm{mg}$ sEGO. For reference, the relationships between percentage removal and mass of adsorbent are given in the Supplementary Material (Fig. S6). Experiments were conducted at an optimum temperature, which was found to be $22.5^{\circ} \mathrm{C}$ (Fig. S7). Previous studies have mainly focused on finding an adsorbent that provides the highest percentage of dye removal and adsorption capacity. ${ }^{6,7}$ This current study investigates the effects of surfactant tail structure variations on the preparation of $\mathrm{SEGO}$ for dye removal in aqueous applications.

\section{Effect of initial dye concentration}

Differences in dye adsorption capacity and initial dye concentration have been probed by studies as a function of dye concentration. It was found that more than $50 \%$ removal could be achieved by AOT14 sEGO and TC14 sEGO at 7, 10, 13 and 15 ppm MB, in contrast to SDS SEGO (see Fig. 1a). The significant removal achieved at such a high initial concentration of $\mathrm{MB}$ (15 ppm) may be attributed to the high ratio of active binding sites to the number of MB molecules, resulting in good adsorbent-adsorbate interactions. ${ }^{45}$ However, at lower initial concentrations of dye $(5,7$ and $10 \mathrm{ppm}$ ), the removal efficiency decreased, suggesting saturation of adsorption sites on the adsorbent by competing adsorbate molecules. ${ }^{45}$ 
Table 2 Comparison of the adsorption capacities of various reported graphene-based adsorbents for MB.

\begin{tabular}{|c|c|c|c|c|c|c|c|c|c|}
\hline Adsorbent & $\begin{array}{l}\text { Source \& } \\
\text { Method }\end{array}$ & $\begin{array}{l}\text { Adsorbent } \\
\text { Dosage } \\
\text { (mg) }\end{array}$ & $\begin{array}{l}\text { Removal } \\
\text { Percentage } \\
(\%) \\
\end{array}$ & $\begin{array}{l}\text { Adsorption } \\
\text { Capacity } \\
\text { (mg/g) }\end{array}$ & $\begin{array}{l}\text { Initial Dye } \\
\text { Concentration } \\
\text { (ppm) }\end{array}$ & $\mathrm{pH}$ & Temperature & $\begin{array}{l}\text { Contact } \\
\text { Time } \\
\text { (min.) }\end{array}$ & Reference \\
\hline TC14 sEGO & $\begin{array}{l}\text { Electrochemical } \\
\text { graphite } \\
\text { exfoliation \& in }\end{array}$ & 5 & 82.7 & 62.1 & $5-15$ & 7 & $23^{\circ} \mathrm{C}$ & 1440 & $\begin{array}{l}\text { This } \\
\text { study }\end{array}$ \\
\hline $\begin{array}{l}\text { AOT14 } \\
\text { sEGO }\end{array}$ & situ method & 5 & 73.9 & 55.5 & $5-15$ & 7 & $23^{\circ} \mathrm{C}$ & 1440 & $\begin{array}{l}\text { This } \\
\text { study }\end{array}$ \\
\hline SDS SEGO & & 5 & 72.4 & 54.3 & $5-15$ & 7 & $23^{\circ} \mathrm{C}$ & 1440 & $\begin{array}{l}\text { This } \\
\text { study }\end{array}$ \\
\hline $\begin{array}{l}\text { SDS- } \\
\text { exfoliated } \\
\text { graphene }\end{array}$ & $\begin{array}{l}\text { Ultrasonic } \\
\text { exfoliation of } \\
\text { graphite \& } \\
\text { dispersion }\end{array}$ & 1.1 & 86.5 & 782.3 & 10,50 and 100 & $\begin{array}{l}3- \\
9\end{array}$ & $25^{\circ} \mathrm{C}$ & 2880 & [15] \\
\hline $\begin{array}{l}\text { Exfoliated } \\
\text { graphene } \\
\text { oxide } \\
\text { (EGO) }\end{array}$ & $\begin{array}{l}\text { Modified } \\
\text { Hummers \& } \\
\text { dispersion }\end{array}$ & 11 & 95 & - & 40 & 6 & - & 160 & {$[42]$} \\
\hline $\begin{array}{l}\text { Exfoliated } \\
\text { graphene }\end{array}$ & $\begin{array}{l}\text { Graphite } \\
\text { exfoliation \& } \\
\text { freeze dried }\end{array}$ & 10 & 105 & 511.70 & 500 & 6 & $\begin{array}{l}\text { Room } \\
\text { temperature }\end{array}$ & 60 & [35] \\
\hline Graphene & $\begin{array}{l}\text { Modified } \\
\text { Hummers \& } \\
\text { dispersion }\end{array}$ & $20-170$ & & 153.85 & $20-120$ & $\begin{array}{l}3- \\
10\end{array}$ & $293 \mathrm{~K}$ & $0-1500$ & {$[46]$} \\
\hline $\begin{array}{l}\text { Graphene } \\
\text { oxide (GO) }\end{array}$ & $\begin{array}{l}\text { Modified } \\
\text { Hummers \& } \\
\text { dispersion }\end{array}$ & 25 & 98 & 243.90 & $40-120$ & 6 & - & $0-350$ & {$[45]$} \\
\hline $\begin{array}{l}\text { Carbon } \\
\text { nanotubes } \\
\text { (CNT) }\end{array}$ & $\begin{array}{l}\text { Ni nanoparticle- } \\
\text { catalysed } \\
\text { pyrolysis }\end{array}$ & 25 & 75 & 188.68 & $40-120$ & 6 & - & $0-350$ & {$[45]$} \\
\hline $\begin{array}{l}\text { Activated } \\
\text { carbon } \\
\text { (AC) }\end{array}$ & $\begin{array}{l}\text { Enteromorpha } \\
\text { prolifera by zinc } \\
\text { chloride } \\
\text { activation }\end{array}$ & 25 & 100 & 270.27 & $40-120$ & 6 & - & $0-350$ & {$[45]$} \\
\hline
\end{tabular}

$\mathrm{MB}$ adsorption onto sEGO reached $72.4 \% \pm 1.8,73.9 \% \pm 0.2$ and $82.7 \% \pm 1.4$ for SDS, АОT14 and TC14 sEGO, respectively, at $15 \mathrm{ppm}$ $M B$. The adsorption capacity at this dye concentration was 62.1 $\mathrm{mg} / \mathrm{g}$ for TC14 sEGO, compared to $55.5 \mathrm{mg} / \mathrm{g}$ for AOT14 sEGO and $54.3 \mathrm{mg} / \mathrm{g}$ for SDS sEGO (see Fig. 1). These results are particularly interesting considering that these $\mathrm{SEGO}$ nanomaterials are can be easily produced compared other approaches (see Table 2 ).

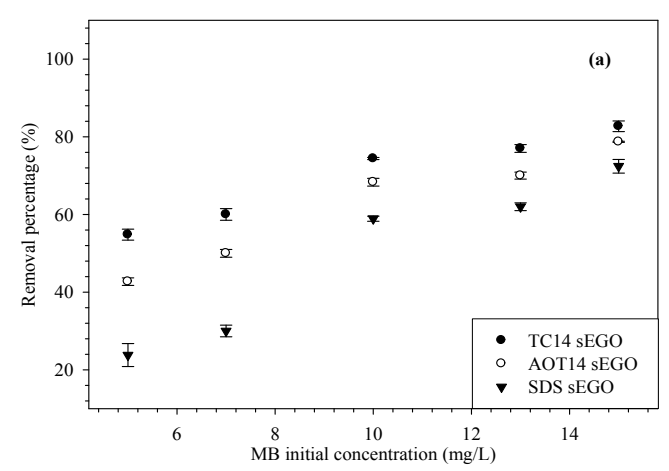

This journal is @ The Royal Society of Chemistry 20xx

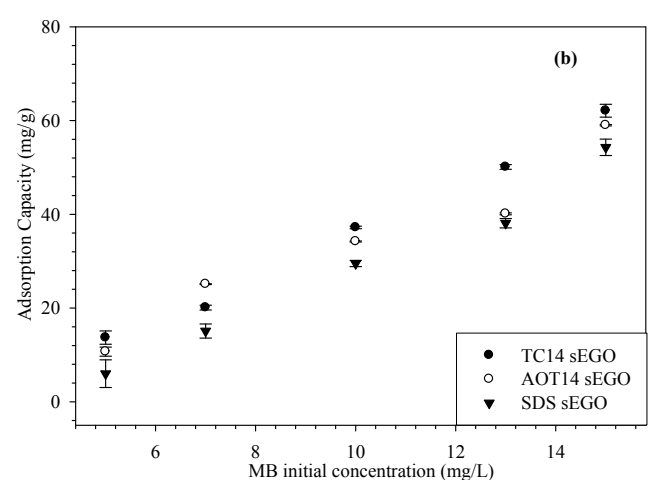

Fig. 1 The percentage removal (a) and adsorption capacity (b) of $M B$ from aqueous dispersion by $s E G O$ containing surfactants at equilibrium dye concentrations with $24 \mathrm{hrs}$. contact time. The error bar represents the standard deviation $(n=3)$.

The expansion of the graphite layers ${ }^{36}$ was mainly caused by the current supply (from the voltammeter) ${ }^{80}$ along with micelle formation and individual surfactant (monomer) activity, whereby these two entities were responsible for the intercalation process. The enhanced performance of TC14 SEGO is attributed to its ability 
to form micelles, facilitating more GO surface area through expansion of the graphite layers ${ }^{36}$ by micelle formation. The presence of surfactant layers on the GO surfaces will also increase the overall negative surface charge. Surface adsorbed surfactant molecules can also function as stabilizers, preventing the agglomeration of SEGO by weakening the $\pi-\pi$ stacking interactions. Hence, these sEGO materials have higher specific surface areas and numbers of accessible adsorbent sites. ${ }^{15}$

\section{Effect of contact time}

To gauge the optimum equilibration time, dye ion binding was studied for contact times from $15-1440 \mathrm{~min}$. (24 hrs.). Samples were taken after $15 \mathrm{~min}$. for the first reading to allow the adsorption process to occur. The time profile of $M B$ adsorption is depicted in Fig. S8. In general, there are two stages: rapid adsorption and then a gradual increase until equilibrium is reached. A high degree of $\mathrm{MB}$ (at $15 \mathrm{ppm}$ ) removal was achieved within the first hour of contact for TC14 SEGO (82.7\%), whereas AOT14 sEGO and SDS sEGO showed removal of 78.7 and $74.7 \%$, respectively. The initially high degree of $\mathrm{MB}$ adsorption indicates essentially instantaneous adsorption, which in turn points to of a surfeit of binding sites on SEGO. Prolonging the contact time showed no obvious increase in removal, implying attainment of equilibrium: either all the active sites had become saturated, or there were no more MB molecules to adsorb. The results imply that a contact time of $24 \mathrm{hrs}$. was more than adequate to achieve saturated adsorption of $\mathrm{MB}$ onto all SEGO adsorbents. The removal of $\mathrm{MB}$ was analysed at particular intervals between $15 \mathrm{~min}$. and $24 \mathrm{hrs}$. is shown in Fig. S8, and as can be seen, after approximately $6 \mathrm{hrs}$. the percentage removal remained constant. 5,6

\section{Adsorption isotherms}

Adsorption isotherm models have been used to describe the adsorption capacities as well as the distribution of MB between the solid and liquid phases at equilibrium. ${ }^{47}$ The Langmuir and Freundlich isotherm models were employed to fit the equilibrium adsorption data. The Langmuir isotherm (eqn (3)) is based on the assumption that adsorption leads to a monolayer coverage of adsorbate on a homogenous adsorbent surface with a finite number of adsorption sites. ${ }^{48}$

$$
\frac{q e}{C_{e}}=K L Q 0-K L q e
$$

where $C_{e}$ is the equilibrium concentration of $\mathrm{MB}(\mathrm{mg} / \mathrm{L}), q_{e}$ is the equilibrium amount of $M B$ ions adsorbed on the adsorbent $(\mathrm{mg} / \mathrm{g})$, $K_{L}$ is the Langmuir constant $(\mathrm{L} / \mathrm{mg})$, and $Q_{0}$ is the maximum monolayer coverage capacity $(\mathrm{mg} / \mathrm{g})$. The significant feature of the Langmuir isotherm is expressed in terms of a dimensionless factor $\left(R_{L}\right)$ as defined in eqn (4), which characterizes the favourability of adsorption $\left(0 \leq R_{L} \leq 1\right)$.

$$
R_{L}=\frac{1}{1+K_{L} C_{0}}
$$

In contrast, the Freundlich isotherm model considers multilayer adsorption on a heterogeneous surface. ${ }^{49}$ The linear form of the Freundlich isotherm is expressed in eqn (5)

$$
\log q_{e}=\frac{1}{n} \log C_{e}+\log K f
$$

where $n$ and $K_{f}$ are the Freundlich parameters and the other quantities have the meanings described above. A linear plot of log $q_{e}$ against $\log C_{e}$ gives $K_{F}$ and $n$. The Langmuir and Freundlich isotherm plots are shown in Fig. S9 ( $a$ and b, respectively), and the calculated parameters from both isotherms are summarized in Table S4.

As shown in Table S4, the adsorption of MB into TC14 sEGO is well described by a Langmuir model with a correlation coefficient $\left(R^{2}\right)$ of 0.99. Either a Freundlich or Langmuir isotherm can be used to describe the adsorption of MB by AOT14 SEGO and SDS SEGO $\left(R^{2}\right.$ is close to 0.9 or 1$)$. These results therefore suggest that all the sEGO surfaces studied act as either homogenous or heterogeneous adsorbents and adsorption resulted in either monolayer or multilayer coverage in the presence of defects (carboxyl, hydroxyl and epoxy functional groups on SEGO layers).

The adsorption behaviour of MB ions onto SEGO surfaces can be further evaluated through a dimensionless constant, the separation factor $\left(R_{L}\right)$, indicating the favourability of adsorption: favourable when $R_{L}=0$, unfavourable when $R_{L}>1$ and linear when $R_{L}=1^{2}$. Since all the $R_{L}$ values are in the range between 0 and $1(0.15$ for TC14 sEGO, 0.18 for AOT14 sEGO and 0.22 for SDS sEGO), adsorption is apparently favourable. In the Freundlich isotherm model, adsorbent heterogeneity is indicated by an $\mathrm{n}$ value approaching zero. ${ }^{2}$ For each of TC14 sEGO, AOT14 sEGO and SDS sEGO $n$ was found to be close to zero, $0.11,0.07$ and 0.04 , respectively. Thus, it can be concluded that adsorption can be well described by both Langmuir and Freundlich adsorption isotherms.

\section{Adsorption kinetics}

To determine the rate of adsorption and the mechanism controlling the adsorption process, pseudo-first- and pseudo-second-order kinetic models were investigated. ${ }^{50}$ It is of interest to understand whether the adsorption involves physisorption (pseudo-first-order kinetic model) or chemisorption (second-order kinetic model). The equations ${ }^{50,53}$ representing these models are

$$
\log \left(q_{e}-q t\right)=\log q e-\frac{k_{1}}{2.303} t
$$

$\frac{t}{q t}=\frac{1}{k 2 q e^{2}}+\frac{t}{q e}$ 
Here, $q_{e}$ and $q_{t}$ are the adsorption capacities at equilibrium and at
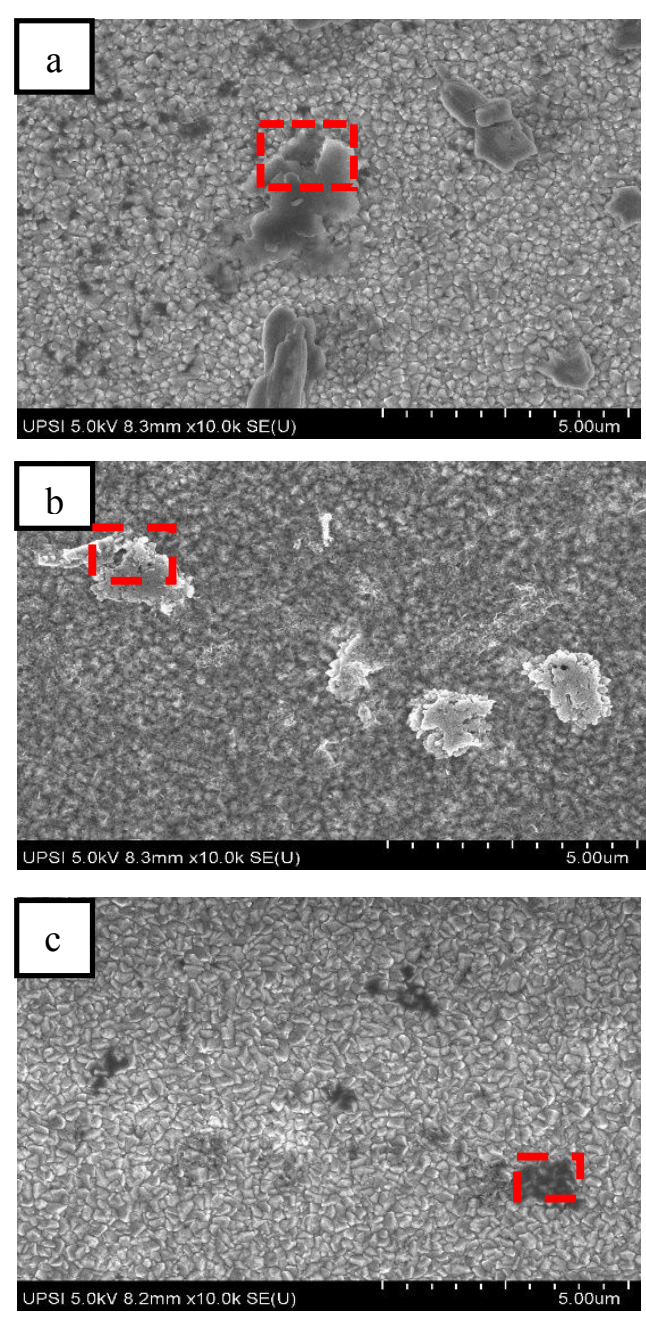

Fig. 2 FESEM images of SDS sEGO ( $a$ and $\left.a^{\prime}\right)$, AOT14 sEGO ( $b$ and $\left.b^{\prime}\right)$ and TC14 SEGO ( $c$ and $\left.c^{\prime}\right)$.

time $\mathrm{t}$, respectively. $k_{1}\left(\mathrm{~min}^{-1}\right)$ and $k_{2}(\mathrm{~g} / \mathrm{mg} \cdot \mathrm{min})$ are the rate constants for the pseudo-first- and pseudo-second-order rate laws. The plots of $\log \left(q_{e}-q_{t}\right)$ and $t / q t$ against $t$ for $\mathrm{MB}$ adsorption at fixed concentrations were linear (Fig. S10), and the calculated values of $k_{2}, q_{e}$ and $R^{2}$ are summarized in Table S4. The results demonstrate that the pseudo-second-order model performs well $\left(R^{2}>0.99\right)$, which is characteristic of chemisorption. $\mathrm{MB}$ is a cationic planar dye molecule with possibilities for $\pi-\pi$ stacking of aromatic rings to provide dipolar interactions with surfactant $s E G O s$ containing hydroxyl, epoxide and carboxyl functional groups. ${ }^{52}$ Montes-Navajaz et al., ${ }^{16}$ proposed that $\mathrm{MB}(\mathrm{pKa}=3.14)$ protonation plays a significant role in the adsorption of $M B$ molecules onto $S E G O$ adsorbents, whereby conjugation between $M B$ and the sEGO surfaces occurs ${ }^{16}$ since $\mathrm{MB}$ consists of sulfur and stabilized nitrogen atoms in a conjugated system.

\section{Observations of sEGO in aqueous solutions}

The morphological features of the SEGOs were observed using FESEM. From the FESEM micrograph in Fig. 2, it can be seen that the surface morphology of sEGO exists as a folded and disorderly sheet-like structure, which is typical for graphene oxide $_{\text {idicle }}^{53}$ The
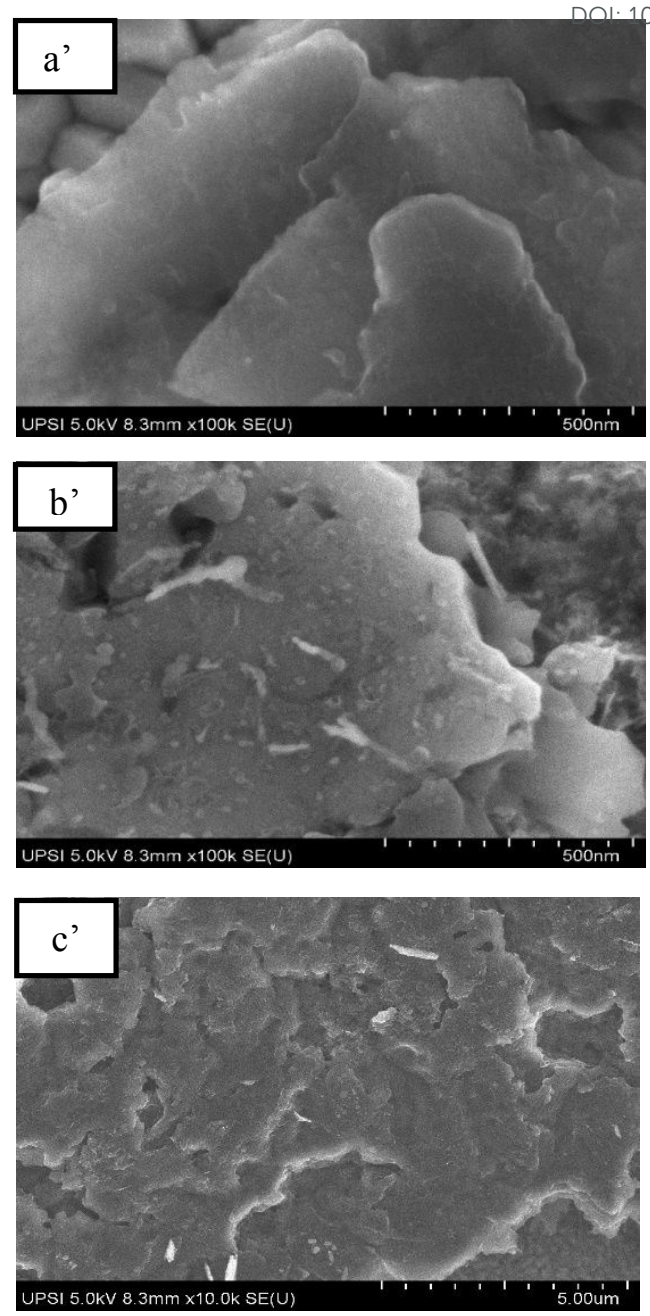
.1039/D0CP01243B

FESEM results for exfoliated graphene were similar to those for GO produced through the Hummers' method:42 the carbon material surfaces displayed ripples and obvious layers, which are distinctive features of graphene and GO. Along with the stacked layers of $s E G O$, the relatively smooth, compact structure and puffy nature of sEGO can also be seen, which is due to the interaction of various oxygen-containing functional groups ${ }^{54}$ originating from the surfactant headgroups. The material with TC14 SEGO has a more expanded structure than for AOT14 SEGO and SDS SEGO. This difference indicates that the TC14 SEGO surface may be richer in oxygenated groups such as hydroxyl, carboxyl, epoxy and carbonyl groups. The FESEM analysis suggests that the surfactants were uniformly embedded between the stacked layers of GO, thereby helping to prevent agglomeration of the GO sheets. ${ }^{55}$ This leads to an increase in effective surface area of SEGOs, which in turn, leads to enhancement of the $\mathrm{MB}$ adsorption. Under high magnification imaging (Fig. 2a'- $\mathrm{c}^{\prime}$ ), there is evidence that the GO sheets still exist as exfoliated thin layers, again confirming that the presence of surfactants helps weaken the van der Waals interactions between adjacent GO sheets. The surfactants are presumed to strongly adsorb onto the GO sheets through electrostatic interactions with 
the oxygen-containing moieties. In addition to being effective as dispersants, surfactants may enhance the adsorption of $M B$ on sEGO surfaces. Unfortunately, a comparison with GO without surfactant cannot be made here, as the exfoliation process requires a charged electrolyte.

\section{Raman spectroscopy}

Structural defects in graphenes, e.g., oxides, ${ }^{53}$ can be investigated with Raman spectroscopy, helping indicate the formation of $s E G O$. According to Lotya et $a l, .^{53}$ the characteristic peaks of carbon nanomaterials lie at approximately $1350 \mathrm{~cm}^{-1}$ and $1582 \mathrm{~cm}^{-1}$, which represent the $D$ band and $G$ band, respectively. Hao et al., ${ }^{56}$ stated that a higher peak intensity of the $G$ band at approximately 1580 $\mathrm{cm}^{-1}$ indicates a greater number of layers due to the presence of more carbon atoms. A broadened $G$ band with increasing $D$ band intensity is attributed to the effect of exfoliation, which leads to a decrease in the in-plane $s p^{2}$ bonding of the graphene..$^{13}$ On the other hand, the presence of the $D$ band is related to the existence of hydroxyl, epoxy and carboxyl functional groups on the graphene layers and can be used to monitor the oxidation process. ${ }^{57}$

Fig. 3 presents the Raman spectra of graphite, TC14 sEGO, AOT14 sEGO and SDS sEGO. Prior to exfoliation, the D band of graphite is negligible compared to the strong $G$ band, indicating small defects and the preservation of the $\mathrm{sp}^{2}$ character of the honeycomb network. In all the sEGO samples exfoliation transforms the appearance of the $D$ bands at $1363 \mathrm{~cm}^{-1}$ : they are broad and strong, confirming oxidation and an evolution of $\mathrm{sp}^{2}$ into $\mathrm{sp}^{3}$ owing to the introduction of oxygen-containing functional groups. ${ }^{58}$ In addition to enhancing the $D$ band, oxidation leads to notable $G$ band intensities at 1583, 1595 and $1611 \mathrm{~cm}^{-1}$ for SDS sEGO, AOT14 sEGO and TC14 sEGO, respectively, compared to that at $1580 \mathrm{~cm}^{-1}$ in pristine graphite.

These peaks correspond to the $E_{2 g}$ vibrational mode occurring in the aromatic carbon rings. In addition, the $G$ bands of the AOT14 and TC14 sEGOs are broader than for graphite, which may indicate that after exfoliation, the structural symmetry decreases along with an increase in vibration modes from destruction of $\mathrm{C}=\mathrm{C}$ bonds. ${ }^{53}$ The significant G band Raman shift for TC14 sEGO is likely due to an increase in $\mathrm{GO}$ layers. ${ }^{59}$ The higher wavenumber of the $\mathrm{G}$ band and the full width half maximum (FWHM) for all SEGOs compared to those of pristine graphite indicate the presence of oxygen. ${ }^{79}$ The FWHM (of the $G$ band) was found to be $25 \mathrm{~cm}^{-1}, 38 \mathrm{~cm}^{-1}, 63 \mathrm{~cm}^{-1}$ and $75 \mathrm{~cm}^{-1}$ for graphite, SDS sEGO, AOT14 sEGO and TC14 sEGO, respectively, suggesting an increase in oxidation level with higher levels of $\mathrm{sp}^{3}$ carbons. ${ }^{79}$

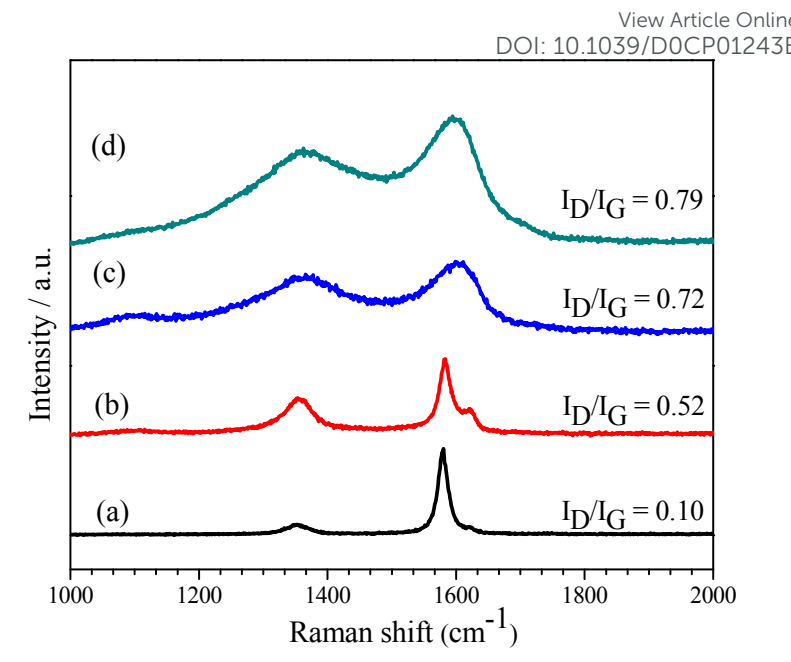

Fig. 3 Raman spectra of graphite (a), SDS SEGO (b), AOT14 sEGO (c), and TC14 sEGO (d).

In addition, calculating the intensity ratio between the $D\left(I_{D}\right)$ and $G$ bands $\left(\mathrm{I}_{\mathrm{G}}\right)$ gives an idea of the defect content and the extent of oxidation. ${ }^{59}$ Since the hexagonal lattice of $\mathrm{C}-\mathrm{C}$ graphene and graphene oxide depends on the hydrogen content based on the connection of $\mathrm{sp}^{2}$ and $\mathrm{sp}^{3}$ linkages, the $\mathrm{I}_{\mathrm{D}} / \mathrm{I}_{\mathrm{G}}$ ratio is sufficient to provide proof for $S E G O .^{80}$ As a result, samples with higher $I_{D} / I_{G}$ values will have higher degrees of disorder and more defects..$^{60}$ Analysis reveals that the graphite starting material presents very low $I_{D} / I_{G}(0.10)$, suggesting high $\mathrm{sp}^{2}$ structural integrity with low levels of basal and edge defects. Moreover, the sEGO samples all show a significant change in the number of defects compared to that in bulk graphite, with $\mathrm{I}_{D} / \mathrm{I}_{\mathrm{G}}$ values of $0.52,0.72$, and 0.79 for SDS sEGO, AOT14 sEGO \& TC14 sEGO, respectively.

Approximation of the oxygen content in SEGO was obtained using UV-visible spectra (Fig. S11). By comparison with literature, ${ }^{20}$ the estimated oxygen contents for TC14 SEGO, AOT14 SEGO and SDS SEGO were $45 \%, 42 \%$ and $21 \%$, respectively. With these results, it is fair to say that the electrochemical exfoliation process assisted by surfactants has successfully peeled graphene layers from bulk graphite and oxidized it to form graphene oxide. The oxygenfunctionalized moieties on $\mathrm{GO}$ then play an important role in promoting the adsorption of MB molecules by the sEGO surfaces.

\section{Zeta potential measurements}

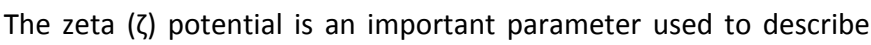
the electrical potential or surface charge of colloidal particles ${ }^{63}$ such as SEGOs. Smith et al., ${ }^{63}$ noted that the height of the electrical potential energy barrier provided by adsorbed surfactant both mitigated the aggregation graphene materials and controlled the level of dispersion of graphene in the aqueous phase, generating stable systems. The stabilisation of $\mathrm{SEGO}$ is due to repulsions between neighbouring surfactant-coated sheets arising from the electrostatic interactions imparted by the dissociated surfactant head- groups ${ }^{62,63,64}$. According to Johnson, Dobson and Coleman, ${ }^{66}$ a high $\zeta$ denotes a large number of surface charges. For ionic 
surfactants, the sign of the zeta potential also reflects the charge and type of the adsorbed surfactant on top of the nanomaterial surface. ${ }^{36} \mathrm{~A}|\zeta|$ value in excess of $30 \mathrm{mV}$ is generally considered to be the threshold for dispersion stability in aqueous systems. ${ }^{23,24}$

To assess the effect of the surfactant on SEGO dispersions, data from a GO dispersion without surfactant taken from the literature ${ }^{67}$ are included as a reference. The measured zeta potentials of the sEGO in this study are summarized in Table S5. Native GO has a $\zeta-$ $20 \pm 1 \mathrm{mV}$, which arises from the presence of surface carboxylate groups. ${ }^{68}$ Interestingly, the presence of surfactant leads to larger negative potentials, implying that $\mathrm{GO}$ suspensions with surfactant are more stable than those without. However, within experimental error, the value for SDS SEGO is very similar to that for native GO, indicating that the linear-chain surfactant was unable to stabilize the $\mathrm{SEGO}$ colloids as well as the custom-made branched surfactants. With a $\zeta$ value of $-46 \mathrm{mV}$, TC14 sEGO clearly has good stability beyond the threshold value ${ }^{69}$ and outperformed both AOT14 sEGO ( $-29 \mathrm{mV})$ and SDS sEGO $(-21 \mathrm{mV})$. It is apparent that there is a trend of increasing stability (i.e., zeta potential value) upon increasing the number of surfactant hydrophobic tails. The reason might be in the Supplementary Material. According to Marcano et $9 l^{78}$ the

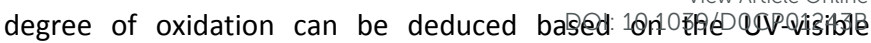
spectrum, where absorbance is proportional to the level of oxygenated groups, which goes in hand with more negative zeta potentials (more colloidally stable) in the sEGO system.

\section{Surface tension measurements}

The surfactant chain structure, such as length, aromatization, branching and methylation, plays a major role in the physicochemical properties, including adsorption, micellization and cmc. ${ }^{55}$ Here, surface tension data also show shifts in $\mathrm{cmc}$ after the formation sEGO systems.

Fig. 4 and Table 3 show surface tension data for SDS, AOT14, and TC14, and their corresponding SEGOs. There are sharp breaks at the cmcs, suggesting the high purity of the synthesised surfactants. ${ }^{39}$ The most highly branched surfactant, TC14, exhibits a $\mathrm{cmc}$ of $18.0 \mathrm{mM}$, followed by double-chain АOT14 (11.0 mM) and single-chain SDS (6.7 mM). Commonly, for a homologous surfactant series an increase in tail carbon number usually leads to a logarithmic decrease in $\mathrm{cmc}^{40,73}$. However, comparisons between different series of surfactants are not always so straightforward. ${ }^{71}$

Table 3 Parameters derived from surface tension measurements including the fractional free volume (FFV).

\begin{tabular}{ccccc}
\hline Surfactant & $\mathrm{cmc}(\mathrm{mM}) \pm 0.03$ & $\gamma_{\mathrm{cmc}}\left(\mathrm{mN} \mathrm{m}^{-1}\right) \pm 1$ & $\mathrm{~A}_{\mathrm{cmc}} / \AA^{2} \pm 2$ & $\mathrm{FFV}$ \\
\hline TC14 & 18.0 & 25.8 & 144 & 0.12 \\
TC14 sEGO & 24.7 & 26.0 & 132 & 0.17 \\
AOT14 & 11.0 & 28.1 & 80 & 0.19 \\
AOT14 sEGO & 15.0 & 30.3 & 64 & 0.30 \\
SDS & 6.7 & 36.1 & 70 & 0.31 \\
SDS sEGO & 8.2 & 37.0 & 61 & 0.37 \\
\hline
\end{tabular}

a higher surfactant chain branching and methylation offer improved barriers and hence higher dispersion stability. It is therefore evident that the surfactant structure, particularly the architecture of the hydrophobic tails, is key to achieving stable suspensions.

Regarding sEGO adsorption properties, it is also clear that there is a trend towards greater MB removal as the degree of chain branching is increased. This suggests that the level of adsorbed MB is linked to stability, and more negative $\zeta$. As indicated in Table S5, the most stable system, TC14 sEGO, showed the highest removal (82.7\%) with an adsorption capacity of $62.1 \mathrm{mg} / \mathrm{g}$. In addition to ensuring the stability of $\mathrm{SEGO}$ in water, the presence of surfactant leads to a more negative overall charge, hence improving electrostatic interactions between $\mathrm{SEGO}$ and $\mathrm{MB}$, thereby conferring dual benefits.

To further support the zeta potential data, all sEGO samples were analysed by UV-visible spectroscopy, and the results are given
Another important parameter for characterizing surfactant performance is the limiting surface tension $\left(\nu_{\mathrm{cmc}}\right)$, representing the effectiveness of any given surfactant for achieving a maximum surface tension reduction. ${ }^{38,72}$ TC14 has the lowest $\gamma_{\mathrm{cmc}}$ value, linked to a low cohesive energy density ${ }^{74}$ between the hydrocarbon chains, leading to easier wetting. 

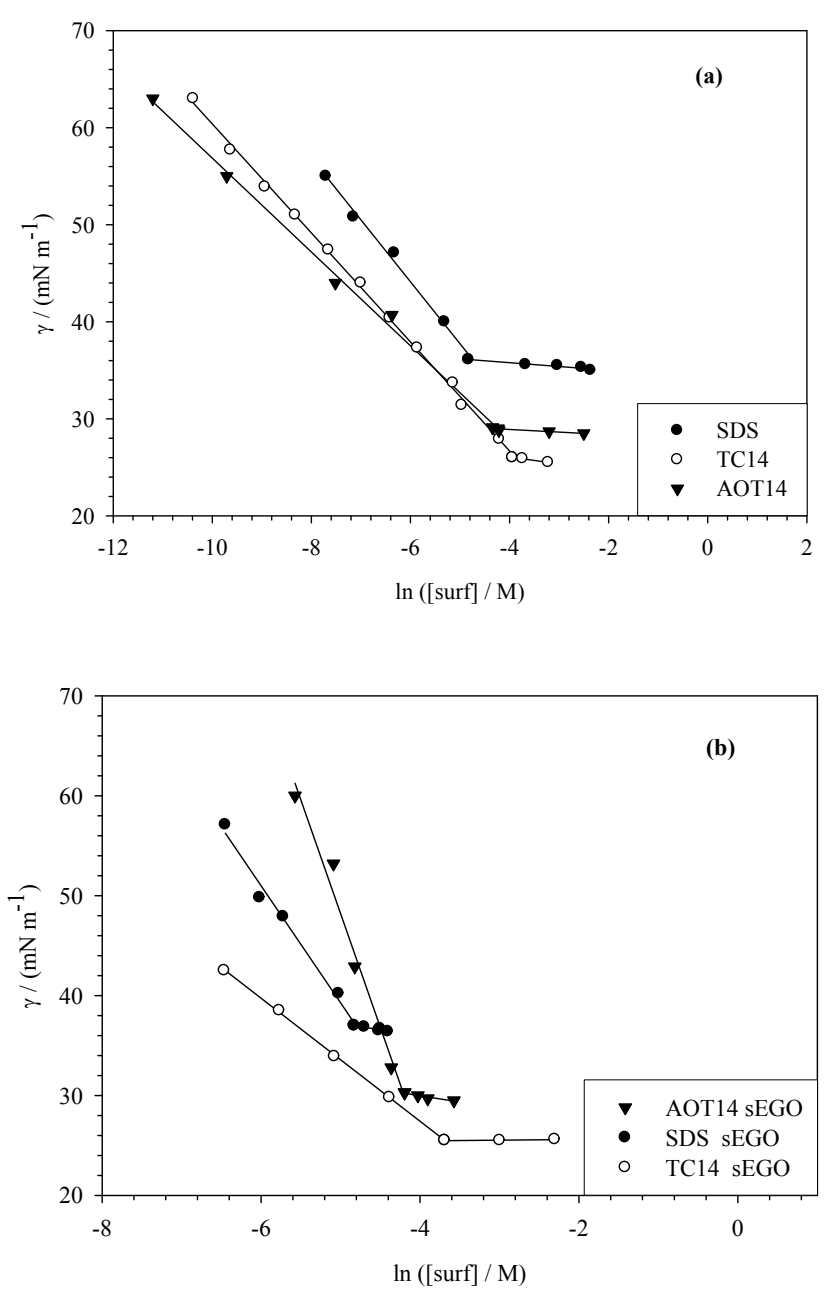

Fig. 4 Air - water surface tension $\gamma_{\mathrm{cmc}}$ vs $\ln$ (concentration) plots for aqueous solutions of surfactants (a) and sEGOs (b) at $25^{\circ} \mathrm{C}$.

Pre-cmc surface tensions can provide estimations of surface excesses, $\Gamma$, and limiting head-group areas at the $\mathrm{cmc}, \mathrm{A}_{\mathrm{cmc}}{ }^{39,74}$ by applying the Gibbs equation (eqn (8)), whereby $m$ is a prefactor for dissociating 1:1 ionic surfactants $=2$. In this way, it is possible to distinguish the molecular packing efficiency in the adsorbed monolayers. Table 3 shows the estimated $A_{c m c}$ calculated using eqn (9).

$$
\Gamma=-\frac{1}{m R T} \frac{d \gamma}{d \ln c}
$$

$$
A_{\mathrm{cmc}}=\frac{1}{\Gamma \mathrm{Na}}
$$

The value of $A_{c m c}$ was found to be much higher for TC14 (144 $\left.\AA^{2}\right)$ and TC14 sEGO (132 $\left.\AA^{2}\right)$ than for the other surfactants and their corresponding sEGOs. A similar observation was previously reported by Czajka et al., ${ }^{75}$ who noted an increases in $A_{c m c}$ of the order of $10-20 \AA^{2}$ for branched surfactants compared to straightchain analogues. The steric effects of the additional chain and also branching in TC14 drives the $A_{c m c}$ higher giving high surface coverages. ${ }^{39}$ Even when GO is present $A_{c m c}$ for triple-branched TC14 is still higher than those of the rest of the series. It can be seen,

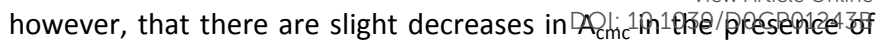
GO (outside the experimental error), suggesting that the surfactants may adsorb on the SEGO layers. Such behaviour was previously noted by Mohamed et al., whereby a decrease in $\mathrm{A}_{\mathrm{cmc}}$ indicated less crowding of head-groups at the interface (perhaps due to reduced repulsive interactions). ${ }^{39}$ This leads to the suggestion that when GO is present, a small fraction of the surfactant molecules at the interface move and adsorb on $\mathrm{GO}$, which leads to weaker headgroup repulsions. Further support for this conclusion comes from the micellar sizes obtained by SANS, described below.

Having established that surfactant adsorption on GO is important for the promotion of dye adsorption by $s E G O$, the effect of surfactant structure will now be considered. The fractional free volume (FFV) is a useful parameter in this respect, since it quantifies "bulkiness" of the surfactant architecture. This FFV concept was first introduced by Johnston, ${ }^{76}$ who proposed that surface coverage and tail geometry are linked to interface stability; a lower FFV value represents better stability. The FFV values for the systems studied here calculated according to eqn (10) are listed in Table 3 , where $V_{t}$ is the surfactant tail volume and $t_{l}$ is the tail length of the surfactant (considering the $\mathrm{C}$ and $\mathrm{H}$ count).

$\mathrm{FFV}=1-\frac{\mathrm{V} t}{\mathrm{t} / \mathrm{Acmc}}$

The calculated FFV values decrease with tail structure, i.e. increased methyl groups and degree of branching. A previous study ${ }^{74}$ using branched surfactants also showed that including chain branching in the tail structure lowered $\nu_{\mathrm{cmc}}$ compared to those of less branched and more linear analogues. The highly branched surfactant TC14 (which is bulkier than AOT14 and SDS) caused an increase in interfacial activity, lowering the interfacial tension and leading to lower FFV values. ${ }^{76}$

\section{Small-angle neutron scattering}

The adsorption of surfactant on nanomaterial surfaces, forming surface micelles, is known to play a crucial role in determining stability. ${ }^{55}$ For this reason, a general picture of micelle formation by surfactants for dispersing and stabilizing sEGO is therefore useful to understand structure and interactions. An ideal technique for studying surfactant micellization is small-angle neutron scattering (SANS).

Fig. 5 displays the SANS data for solutions of the surfactants used in this study (SDS, AOT, and TC14) and the respective sEGO suspensions for comparison. The parameters obtained from fitting the SANS data are provided in Table 4. According to Stone et al., ${ }^{76}$ the shape, volume and contrast of the nanoscale structures were assessed from the scattering intensities $I(Q)$. Over the $Q$ range in Fig. 5 (a), there are minor changes in I(Q) for TC14 sEGO compared to that of TC14 (at the $\mathrm{cmc}$ ), consistent with a smaller micelle size, based on judgement by Mc Coy et al. ${ }^{77}$ The small increase in I(Q) in the low $Q$ region can be interpreted as a result of surfactant adsorption indicative of sEGO formation. To further support this 
Table 4 Model fit parameters for the SANS data

\begin{tabular}{|c|c|c|c|c|c|c|c|c|}
\hline Journample & Model & $R_{\text {sphere }}(\AA)$ & $R_{a}{ }^{\mathrm{a}}(\AA ̊)$ & $R_{b}^{\mathrm{b}}(\AA)$ & $X^{c}$ & $L^{d}$ & $D^{d}$ & $\overline{M_{\mathrm{ARTICLE}}^{d}}$ \\
\hline \multicolumn{9}{|c|}{ Surfactant solution } \\
\hline SDS & Sphere & 22.0 & - & - & - & \multicolumn{3}{|c|}{$\begin{array}{r}\text { View Article Online } \\
\text { DOI: 10:1039/DOCPO1243B }\end{array}$} \\
\hline AOT14 & $\begin{array}{l}\text { Paracrystalline } \\
\text { lamellar stack }\end{array}$ & - & - & - & - & 6.0 & 90.0 & 27.0 \\
\hline TC14 & Ellipsoid & - & 10.0 & 20.4 & 2.0 & - & - & - \\
\hline \multicolumn{9}{|l|}{$s E G O$} \\
\hline SDS sEGO & Sphere & 24.0 & - & - & - & - & - & - \\
\hline AOT14 sEGO & $\begin{array}{l}\text { Paracrystalline } \\
\text { lamellar stack }\end{array}$ & - & - & - & - & 9.0 & 61.0 & 484.0 \\
\hline TC14 sEGO & Ellipsoid & - & 8.0 & 23.0 & 2.9 & - & - & - \\
\hline
\end{tabular}

\section{a Polar radius}

${ }^{\mathrm{b}}$ Equatorial radius

${ }^{\mathrm{c}} X=R_{b} / R_{a}$

${ }^{\mathrm{d}}$ For lamellar only, where $\mathrm{L}=$ thickness of bilayers; $\mathrm{D}=$ space between bilayers; and $\mathrm{M}=$ number of bilayers

statement, TC14 sEGOs produced using TC14 at a lower $\mathrm{cmc}$ were analysed and demonstrated the absence of structured materials. The lack of obvious changes in the AOT14 and AOT14 sEGO I(Q) profiles indicate bulk micelle formation. However, a bump appears in the pure SDS solution plot compared to that of SDS SEGO, which can be assumed to arise from an increase in intermicellar interactions. There is also a bump in the profile for the AOT14 solution, but this is less prominent with added SEGO, as indicated by fitting the Hayter-Penfold charge repulsion S(Q). SANS data for each individual surfactant and its corresponding sEGO for comparison can be found in Fig. 5.

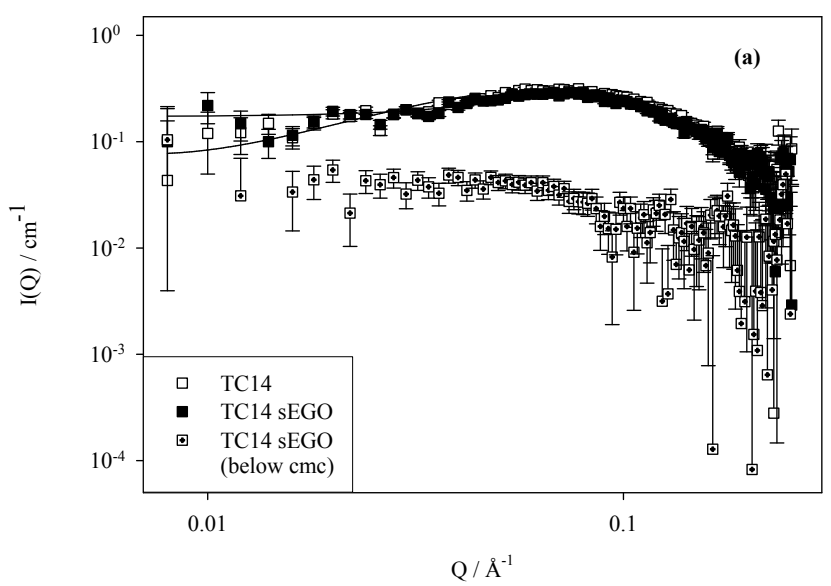

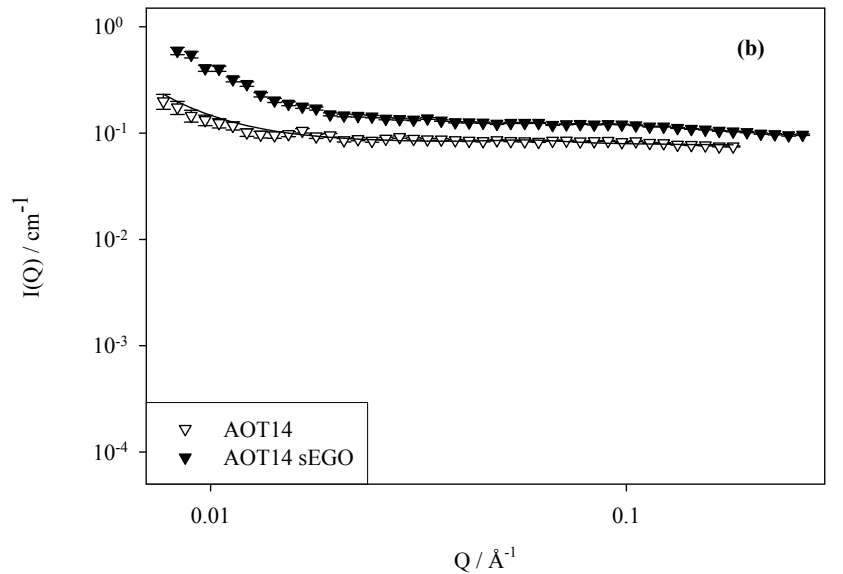

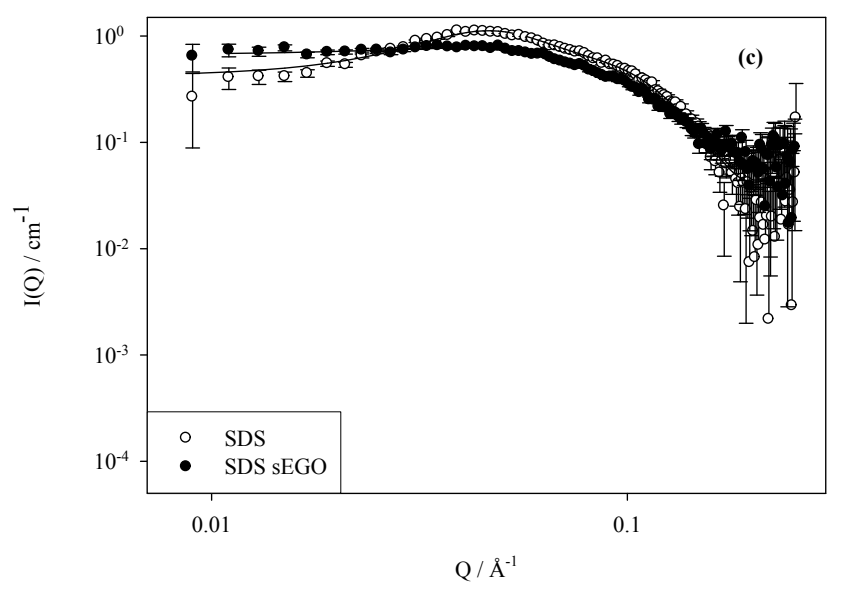

Fig. 5 SANS data for (a) TC14, TC14 sEGO and TC14 sEGO (below cmc), (b) AOT14 and AOT14 sEGO, (c) SDS and SDS sEGO. [Surfactant] $=30 \mathrm{mM}$ (at $\mathrm{cmc}$ ), while [Surfactant] $=0.75 \mathrm{mM}$ (below (mc); $[\mathrm{sEGO}]=0.2 \mathrm{mg} / \mathrm{mL}$ at $\mathrm{T}=25^{\circ} \mathrm{C}$. Lines are model fits for spherical, paracrystalline lamellar stacked and ellipsoidal micelles (incorporating a Hayter-Penfold $S(Q)$ ). Characteristic error bars are shown for the lowest intensity samples. 
The scattering from SDS is characteristic of approximately spherical but charged micelles with a radius of $22.0 \AA$, in accordance with previous studies. ${ }^{32-34}$ The shape and size of the micelles remain essentially unchanged when SEGO is formed, consistent with previous findings. ${ }^{36}$ The same reasoning applies to AOT14 and TC14, where both profiles could be fitted to paracrystalline lamellar stack and ellipsoid models, respectively, with the micelle reason, we showed here that for such a small surfactant molecule, the exfoliation efficiency can be controlled structure. Increasing the degree of the surfactant hydrophobic chain has been shown to improve the exfoliation efficiency ${ }^{32,36}$ as well as the adsorption capacity/dye uptake during batch adsorption studies.

Combining the aforementioned research with the current

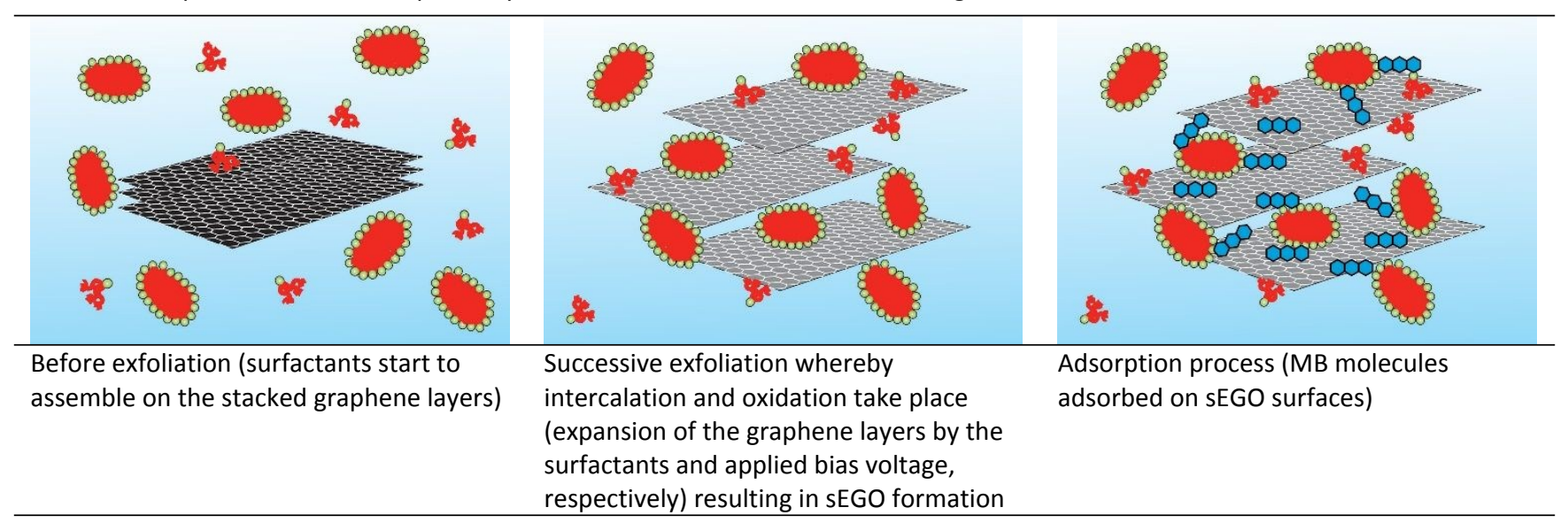

Fig. 6 Schematic representation, not to scale, of surfactant-mediated graphene exfoliation to form sEGO and the uptake of methylene blue by sEGO.

characteristics remaining in the sEGO system. These findings were also proven by previous research performed by Ardyani et al., ${ }^{32}$ in which graphene oxide was invisible or 'contrast-matched' since there were no distinct changes in scattering. SANS data provide structural information, but not explicit adsorption mechanisms; however, GO could act as an aqueous adsorbent on the basis of the differences in scattering between the SEGO composite and pure surfactants. ${ }^{77}$

\section{Proposed adsorption and exfoliation mechanism}

Previous studies ${ }^{80}$ suggested a two-step exfoliation mechanism, whereby first, the formation of nucleophilic hydroxyl ions $\left(\mathrm{OH}^{-}\right)$ through aqueous reduction created in the electrolyte (in this case, surfactant solution) occurs at the graphite edges. Next, oxidation generated graphite layer expansion takes place, which then assists sulfate ion $\left(\mathrm{SO}_{4}{ }^{2-}\right)$ intercalation between the graphite sheets. Cointercalation between $\mathrm{SO}_{4}{ }^{2-}$ and water might also have occurred during this stage. Generally, the current flow produced during the electrochemical exfoliation process causes surfactant ion interactions between the graphite layers in the graphite rods. ${ }^{36} \mathrm{Li}$ et al., ${ }^{81}$ found that the use of an electrolyte for the electrical exfoliation of graphite made using commercial sodium dodecylbenzene sulfonate (SDBS) would result in intercalation and stabilize the colloidal environment (dual role function). For that results, we propose how to adapt the structure of surfactants to promote both efficient exfoliation and adsorption. Previous studies have successfully used this strategy to tailor graphene compatibility. ${ }^{40}$ Now, with growing attention to these systems it is of interest to know which combination of graphene and surfactants for generating $S E G O$ will be most effective for a potential $M B$ scavengers. The previous discussions on SEGO morphologies and properties based on FESEM, Raman spectroscopy, zeta potential measurements, micellar sizes and shapes using SANS, and surface tension measurements were interpreted in terms of adsorption of surfactant ions which charge the graphene layers, ${ }^{67}$ hence in turn providing adsorption sites for MB.

Thus, the proposed exfoliation mechanism is presented in Fig. 6 . Electrochemical exfoliation takes place by surfactant intercalation between graphite rod electrode layers ( $7 \mathrm{~V}$ power supply employed for $24 \mathrm{hrs}$ ). ${ }^{36}$ The graphite edge sheets open up through the applied bias voltage and prepared electrolyte (surfactant solution),, 80 whereby the triple-chain surfactant TC14 enters the interlayer spacing. Further sEGO expansion occurs under ultrasonication. ${ }^{36,42}$

The simple geometric parameter fraction free volume (FFV) is also useful for understanding the behaviour of these systems. As mentioned before, based on FFV, the effective TC14 molecular size is lower (FFV 0.12) than that of TC14 SEGO (FFV 0.17), indicating a greater efficiency for filling space. Consistent with this property, the 
highly branched triple-chain TC14 surfactant tail adsorbs onto the graphene sheets more effectively (whilst the head-group resides in the aqueous phase), as compared to double-chain AOT14 (FFV = 0.19 ) and single-chain SDS (FFV $=0.31$ ), with FFV values for AOT14 SEGO and SDS SEGO of 0.30 and 0.37 , respectively. During the exfoliation process, it is suggested that surfactant ions expand the graphene layers, hence forming sEGO composites.

The fundamental mechanisms controlling MB adsorption on the sEGO surface at $\mathrm{pH} 7$ include i) electrostatic interactions between the positively charged $\mathrm{N}^{+}$groups of $\mathrm{MB}$ and the inherently negatively charged SEGO (from the $-\mathrm{O}_{3} \mathrm{~S}^{-}$in the surfactant headgroup), ii) $\pi-\pi$ stacking interactions between sEGO layers by the $\mathrm{MB}$ aromatic rings and iii) hydrophobic interactions between hydrophobic parts of $\mathrm{MB}$ (benzyl groups) and hydrophobic parts of surfactant sEGOs ( $-\mathrm{CH}_{3}$ and $-\mathrm{CH}_{2}$ - groups and hydrocarbon tails). Although the adsorption capacity of $\mathrm{MB}$ from aqueous solution has been proven through batch experiments, just how much of the adsorption was due to binding of $M B$ to the surfactant is hard to evaluate. Further studies on this issue are required.

\section{Conclusions}

In this work, surfactant chain structure and branching ${ }^{40,73}$ were proven to affect interactions, ${ }^{32}$ thereby tailoring the structures and properties of surfactant-graphene oxide composites (sEGOs). The structural changes induced by surfactant type also affect the capacity and effectiveness of the SEGOs as adsorbents for the model pollutant dye methylene blue (MB). It was found that a highly branched tri-chain surfactant, TC14, conferred TC14 sEGOs with a much higher adsorption capacity than composites generated with a common linear single-chain compound SDS. This shows that surfactant design can beneficially affect the properties of exfoliated sEGOs, paving the way for tailored improvements in applications of these systems as adsorbents for aqueous pollutants. Although the adsorption and removal capacities shown here were not as high as those of some other carbon nanoadsorbents, ${ }^{16,43,46,47,49}$ there are other advantages, especially a much more straightforward exfoliation and production process. As such, the approach described here opens up new avenues for the wider applications of sEGOs, in for example in wastewater treatment.

\section{Conflicts of interest}

There are no conflicts to declare.

\section{Acknowledgements}

This work was funded under a grant from Universiti Pendidikan Sultan Idris Rising Star Research Grant (Grant Code: 20190118-103-01). This project was also supported by JSPS [KAKENHI, Grant-in-Aid for Young Scientists (A), No 23685034] and Leading Research Organizations (RCUK [through EPSRC EP/I018301/1], ANR[13-G8ME0003]) under the G8 Research Councils Initiative for Multi-lateral Research Funding-G8-
2012. The authors thank the Science and Technology AFacilities Council for the allocation of beamoltime, 39 travep1zara consumables (experiment number RB1710004). This work benefited from the use of the SasView application, originally developed under NSF Award DMR-0520547. SasView also contains code developed with funding from the EU Horizon 2020 programme under the SINE2020 project Grant No. 654000 .

\section{Notes and references}

1 S. Song, Y. Ma, H. Shen, M. Zhang, and Z. Zhang, RSC Adv., 2015, 5, 27922-27932.

2 A. B. Albadarin, J. Mo, Y. Glocheux, S. Allen, G. Walker, and C. Mangwandi, Chem. Eng. J., 2014, 255, 525-534.

3 M. Ghaedi, H. Mazaheri, S. Khodadoust, S. Hajati, and M. K. Purkait, Spectrochim Acta A, 2015, 135, 479-490.

4 X. Wang. Y. Liu, H. Pang, S. Yu, Y. Ai, X. Ma, G. Song, T. Hayat, A. Alsaedi, X. Wang, Chem. Eng. J., 2018, 344, 380-390.

5 W. Xiao, B. Yan, H. Zeng, and Q. Liu, Carbon, 2016, 105, 655664.

6 J. A. González, M. E. Villanueva, L. L. Piehl, and G. J. Copello, Chem. Eng. J., 2015, 280, 41-48.

7 M. T. Yagub, T. K. Sen, S. Afroze, and H. M. Ang, Advances in Colloid and Interface Science, 2014, 209, 172-184.

8 G. Z. Kyzas, D. A. Eleni, and M. A. Kostas, Journal of Chemical Technology and Biotechnology, 2014, 89, 196-205.

9 G. Crini, Bioresource Technology, 2006, 97, 1061-1085.

10 M. Yusuf, F. M. Elfghi, S. A. Zaidi, E. C. Abdullah, and M. A. Khan, RSC Advances, 2015, 5, 50392-50420.

11 K. S. Novoselov, A. K. Geim, S. V. Morozov, D. Jiang, Y. Zhang, S. V. Dubonos, I. V. Grigorieva, A. A. Firsov, Science, 2004, 306, 666-669.

12 S. V. Tkachev, E. Y. Buslaeva, and S. P. Gubin, Inorganic Materials, 2011, 47, 1-10.

13 S. Stankovich, D. A. Dikin, R. D. Piner, K. A. Kohlhaas, A. Kleinhammes, Y. Jia, y. Wu, S. T. Nguyen and R. S. Ruoff, Carbon, 2007, 45, 1558-1565.

14 Y. Hernandez, M. Lotya, D. Rickard, S. D. Bergin, and J. N. Coleman, Langmuir, 2010, 26, 3208-3213.

15 A. Y. W. Sham and S. M. Notley, Journal of Environmental Chemical Engineering, 2018, 6, 495-504.

16 P. Montes-Navajas, N. G. Asenjo, R. Santamaria, R. Menendez, A. Corma, and H. Garcia, Langmuir, 2013, 29, 13443-13448.

17 L. Wu, L. Liu, B. Gao, R. Muñoz-Carpena, M. Zhang, H. Chen, Z. Zhou, and H. Wang, Langmuir, 2013, 29, 15174-15181.

18 G. Hazell, M. Hinojosa-Navarro, T. M. McCoy, R. F. Tabor, and J. Eastoe, Journal of Colloid and Interface Science, 2016, 464, 285-290.

19 K. W. J. Heard, C. Bartlam, C. D. Williams, J. Zhang, A. A. Alwattar, M. S. Little, A. V. S. Parry, F. M. Porter, M. A. Vincent, I. H. Hiller et al., ACS Omega, 2019, 4, 1969-1981.

20 J. Chen, B. Yao, C. Li, and G. Shi, Carbon, 2013, 64, 225-229.

21 J. Chen, Y. Li, L. Huang, C. Li, and G. Shi, Carbon, 2015, 81, 826-834.

22 W. Liu, H. Li, C. Xu, Y. Khatami, and K. Banerjee, Carbon, 2011, 49, 4122-4130.

23 I. Vlassiouk, P. Fulvio, H. Meyer, N. Lavrik, S. Dai, P. Datskos, S. Smirnov, Carbon, 2012, 54, 58-67.

24 W. Yang. G. Chen, Z. Shi, C. Liu, L. Zhang, G. Xie, M. Cheng, D. Wang, R. Yang, D. Shi et al., Nature Materials, 2013, 12, 792797.

25 Y. Hernandez, V. Nicolosi, M. Lotya, F. M. Blighe, Z. Sun, S. De, I. T. McGovern, B. Holland, M. Byrne, Y. K. Gun'Ko et al., Nature Nanotechnology, 2008, 3, 563-568. 
26 L. Guardia, M. J. Fernández-Merino, J. I. Paredes, P. Solís Fernández, S. Villar-Rodil, A. Martínez-Alonso, J. M. D. Tascón, Carbon, 2011, 49, 1653-1662.

27 S. Sampath, A. N. Basuray, K. J. Hartlieb, T. Aytun, S. I. Stupp, and J. F. Stoddart, Advanced Materials, 2013, 25, 2740-2745.

28 R. Narayan, J. Lim, T. Jeon, D. J. Li, and S. O. Kim, Carbon 2017, 119, 555-568.

29 N. Liu, F. Luo, H. Wu, Y. Liu, C. Zhang, and J. Chen, Advanced Functional Materials, 2008, 18, 1518-1525.

30 J. Liu, M. Notarianni, G. Will, V. T. Tiong, H. Wang, and N. Motta, Langmuir, 2013, 29, 13307-13314.

31 A. T. Najafabadi and E. Gyenge, Carbon, 2014, 71, 58-69.

32 T. Ardyani, A. Mohamed, S. A. Bakar, M. Sagisaka, Y. Umetsu, M. H. Mamat, M. K. Ahmad, H. P. S. A. Khalil, S. M. King et al., Carbohydrate Polymer, 2020, 228, 115376.

33 K. Parvez, R. Li, S. R. Puniredd, Y. Hernandez, F. Hinkel, S Wang, X. Feng and K. Müllen, ACS Nano, 2013, 7, 3798-3606.

34 J. Gong, X. Gao, M. Li, Q. Nie, W. Pan, and R. Liu, International Journal of Environmntal Science and Technology, 2017, 14, 305-314.

35 Z. Xue, S. Zhao, Z. Zhao, P. Li, and J. Gao, Journal of Materials Science, 2016, 51, 4928-4941.

36 A. Mohamed, T. Ardyani, S. A. Bakar, M. Sagisaka, Y. Umetsu, M. R. M. Hussin, M. K. Ahmad, M. H. Mamat, S. King, A. Czajka et al., Cabohydrate Polymer, 2018, 201, 48-59.

37 T. Ardyani, A. Mohamed, S. A. Bakar, M. Sagisaka, Y. Umetsu, M. H. Mamat, M. K. Ahmad, H. P. S. A. Khalil, S. King, S. E. Rogers et al., Journal of Colloid and Interface Science, 2019, 545, 184-194.

38 L. Zhang, Z. Zhang, C. He, L. Dai, J. Liu, and L. Wang, ACS Nano, 2014, 8, 6663-6670.

39 A. Mohamed, K. Trickett, S. Y. Chin, S. Cummings, M. Sagisaka, L. Hudson, S. Nave, R. Dyer, S. E. Rogers, R. K. Heenan et al., Langmuir, 2010, 26, 13861-13866.

40 A. Mohamed, A. K. Anas, S. A. Bakar, A. A. Aziz, M. Sagisaka, P. Brown, J. Eastoe, A. Kamari, N. Hashim and I. M. Isa, Colloid and Polymer Science, 2014, 292, 3013-3023.

41 A. B. Suriani, M. D. Nurhafizah, A. Mohamed, A. K. Masrom, V. Sahajwalla, and R. K. Joshi, Materials and Design, 2016, 99, 174-181.

42 G. K. Ramesha, A. V. Kumara, H. B. Muralidhara, and S. Sampath, Journal of Colloid and Interface Science, 2011, 361, 270-277.

43 W. Konicki, M. Aleksandrzak, and E. Mijowska, Chemical Engineering Research and Design, 2017, 123, 35-49.

44 K. Haubner, J. Murawski, P. Olk, L. M. Eng, C. Ziegler, B. Adolphi and E. Jaehne, Chem Phys Chem, 2010, 11, 21312139.

45 Y. Li, Q. Du, T. Liu, X. Peng, J. Wang, J. Sun, Y. Wang, S. Wu, Z. Wang, Y. Xia et al., Chemical Engineering Research and Design, 2013, 91, 361-368.

46 W. Konicki, M. Aleksandrzak, D. Moszyński, and E. Mijowska, Journal of Colloid and Interface Science, 2017, 496, 188-200.

47 K. Y. Foo and B. H. Hameed, Chemical Engineering Journal, 2010, 156, 2-10.

48 I. Langmuir, Journal of the American Chemical Society, 1918, 40, 1361-1403.

49 H. Freundlich, The Journal of Physical Chemistry A, 1906, 57, 1100-1107.

50 J. Zhang, Y. Zhou, M. Jiang, J. Li, and J. Sheng, Journal of Molecular Liquids, 2015, 209, 267-271.

51 Y. S. Ho, Journal Hazardous Materials, 2006, 136, 681-689.

52 S. Bai, X. Shen, X. Zhong, Y. Liu, G. Zhu, X. Xu and K. Chen, Carbon, 2012, 50, 2337-2346.

53 M. Lotya, Y. Hernandez, P. J. King, R. J. Smith, V. Nicolosi, L. S Karlsson, F. M. Blighe, S. De, Z. Wang, I. T. McGovern et al., Journal of the American Chemical Society, 2009, 131, 36113620.
54 J. N. Coleman, Advanced Functional Materials, 200919 3680-3695.

DOI: 10.1039/DOCP01243B

55 A. Mohamed, T. Ardyani, S. A. Bakar, M. Sagisaka, Y. Umetsu, J. J. Hamon, B. A. Rahim, S. R. Esa, H. P. S. A. Khalil, M. H. Mamat et al., Journal of Colloid and Interface Science, 2018, 516, 34-47.

56 Y. Hao, Y. Wang, L. Wang, Z. Ni, Z. Wang, R. Wang, C. K. Koo, Z. Shen and J. T. L. Thong, Small, 2010, 6, 195-200.

57 C. Soldano, A. Mahmood, and E. Dujardin, Carbon, 2010, 48 2127-2150.

58 V. C. Tung, M. J. Allen, Y. Yang, and R. B. Kaner, Nature Nanotechnology, 2009, 4, 25-29.

59 A. C. Ferrari and J. Robertson, Physical Review B, 2001, 64, 113.

60 Y. Zhu, S. Murali, W. Cai, X. Li, J. W. Suk, J. R. Potts and R. S. Ruoff, Advanced Materials, 2010, 22, 3906-3924.

61 R. J. Smith, M. Lotya, and J. N. Coleman, New Journal of Physics, 2010, 12.

62 R. J. Hunter, Introduction to modern colloid science. Oxford University Press, 1993.

63 J. N. Israelachvili, Intermolecular and surface foces, vol. 59. Academic Press, 2011.

64 D. W. Johnson, B. P. Dobson, and K. S. Coleman, Current Opinion in Colloid and Interface Science, 2015, 20, 367-382.

65 D. Li, M. B. Müller, S. Gilje, R. B. Kaner, and G. G. Wallace, Nature Nanotechnology, 2008, 3, 101-105.

66 Z. Sun, V. Nicolosi, D. Rickard, S. D. Bergin, D. Aherne, and J. N. Coleman, The Journal of Physical Chemistry C, 2008,112, 10692-10699.

67 F. Zhang, S. Li, Q. Zhang, J. Liu, S. Zeng, M. Liu and D. Sun, Journal of Molecular Liquids, 2019, 276, 338-346.

68 F. Baskoro, C. Wong, S. R. Kumar, C. Chang, C. Chen, D. W. Chen and S. J. Lue, Journal of Membrane Science, 2018, 554, 253-263.

69 Y. Si and E. T. Samulski, Nano Letters, 2008, 8, 1679-1682.

70 J. Eastoe, A. Paul, A. Downer, D. C. Steytler, and E. Rumsey, Langmuir, 2002, 7, 3014-3017.

71 S. Gold, J. Eastoe, R. Grilli, and D. C. Steytler, Colloid Polymer Science, 2006, 284, 1333-1337.

72 M. J. Rosen, Surfactants and interfacial phenomena, John Wiley \& Sons Inc., NY, 2004.

73 D. Myers, Surfactant science and technology, John Wiley \& Sons, Inc., Hoboken, New Jersey, 1385.

74 A. Mohamed, M. Sagisaka, M. Hollamby, S. E. Rogers, R. K. Heenan, R. Dyer and J. Eastoe, Langmuir, 2012, 28, 62996306.

75 A. Czajka, G. Hazell, and J. Eastoe, Langmuir, 2015, 31, 82058217.

76 M. T. Stone, P. G. Smith, S. R. P. Rocha, P. J. Rossky, and K. P. Johnston, The Journal of Physical Chemistry B, 2004, 108 1962-1966.

77 T. M. McCoy, L. De Campo, A. V. Sokolova, I. Grillo, E. I. Izgorodina, and R. F. Tabor, Physical Chemistry Chemical Physics, 2018, 20, 16801-16816.

78 D. C. Marcano, D. V. Kosynkin, J. M. Berlin, A. Sinitskii, Z. Sun, A. Slesarev, L. B. Alemany, W. Lu and J. M. Tour, ACS Nano, 2010, 4, 4806-4814.

79 K. Krishnamoorthy, M. Veerapandian, K. Yun and S. J. Kim, Carbon, 2013, 53, 38-49.

80 A. M. Abdelkader, A. J. Cooper, R. A. W. Dryfe and I. A. Kinloch, Nanoscale, 2015, 7, 6944-6956.

81 P. Li, S. H. Bae, Q. Y. Zan, N. H. Kim and J. H. Lee, Advanced Materials Research, 2010, 123-125, 743-746. 

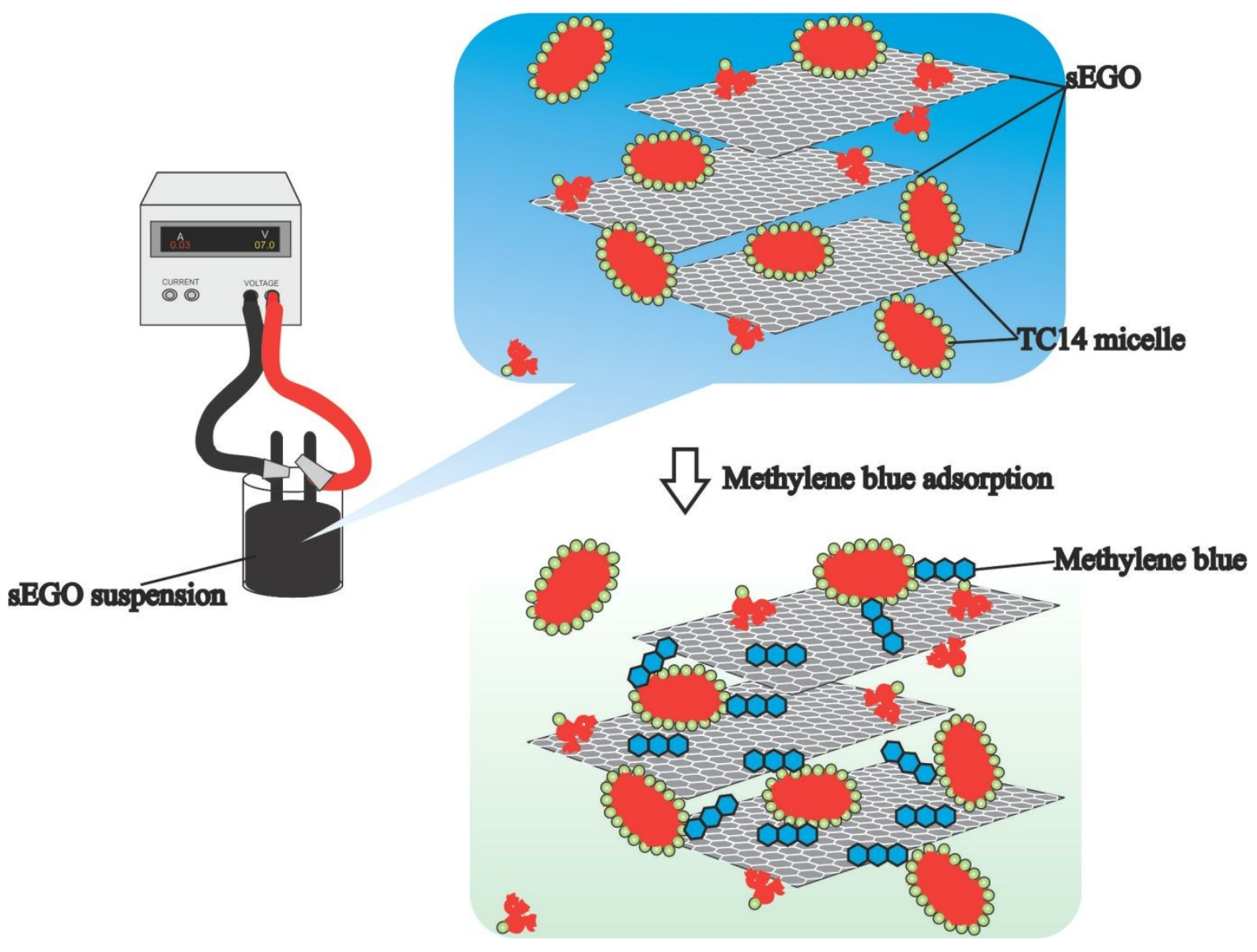